\title{
Artículo Especial: Obras maestras del arte universal y la medicina: \\ La transformación de Franz Kafka (1883-1924)
}

Universal Art Masterpieces and Medicine: "The transformation" by Franz Kafka (1883-1924)

Carlos Musso*

\begin{abstract}
Argumento
Gregor Samsa es un viajante de comercio que con su trabajo sostiene económicamente a su hermana y a sus padres con quienes además comparte su casa. Pero un día, súbita e inexplicablemente Gregor despierta y se da cuenta que se ha transformado en un monstruoso insecto. A consecuencia de su "transformación" pierde su empleo, razón por la cual el resto de la familia debe comenzar a trabajar para procurar el sustento colectivo. Al comienzo, Gregor está más preocupado por haberse transformado en alguien inservible para su familia y la sociedad, más que por la naturaleza de su nueva condición. Poco a poco comienza a adaptarse a sus recientemente adquiridas características físicas y funcionales, mientras que curiosamente su familia, por la cual tanto sacrificio había hecho, reacciona en forma diversa ante su fatalidad: su padre lo hace con enojo, su madre con temor y su hermana con compasión. Sin embargo, con el correr del tiempo estas actitudes sufren también una "transformación": el enojo paterno deviene agresión física -llega incluso a herirlo de gravedad en su espalda-, el temor materno se torna desinterés y la compasión fraterna se transmuta en hastío. Tras tres meses de tensión, la familia se agota llegando incluso a desear la desaparición de Gregor. Éste percibe claramente la situación, cayendo en un pozo depresivo, el cuál junto al agravamiento de su herida, lo conduce a un deterioro progresivo, agonía y muerte. La familia vive este desenlace con gran alivio y renovada esperanza en el futuro.
\end{abstract}

\section{Algunas consideraciones preliminares}

Se ha difundido una versión errónea en español del titulo original de esta obra (die Verwandlung) como "la metamorfosis", en lugar de "la transformación", que es en realidad su correcta traducción. No se trata de una sutiliza lingüística sino de una cambio rotundo de sentido. El uso de la palabra metamorfosis induce al lector a pensar que se trata de un relato de estilo fantástico o surrealista, cuando en realidad salvo por la transmutación (metafórica) de Gregor en un insecto, su estilo es profundamente realista. No debemos confundir el absurdo humano (tristemente real) con lo fantástico. Así lo demuestra el hecho de que existiendo la palabra alemana Metamorphose, Kafka no la haya elegido para titular su relato. Otra prueba de esto es que en el relato se percibe claramente que son todos los miembros de la familia Samsa y no sólo Gregor, quienes sufren una transformación actitudinal tan cruda como humana, y que dista mucho de corresponder al orden de lo fantástico (metamorfosis). Por otra parte, existe otra diferencia fundamental entre ambos términos: una transformación remite a una situación mucho más angustiosa (kafkiana) que una metamorfosis por el mayor grado de incertidumbre que connota: mientras que en una metamorfosis el cambio que se avecina es esperable y sujeto a reglas -por ejemplo, la larva que deviene mariposa-, por el contrario en una transformación el cambio es impredecible en tiempo y forma.

Mucho se ha discutido acerca de la naturaleza de la transformación que sufre Gregorio Samsa, pero hay dos puntos que parecen claros: la transformación sería metafórica, pues se trataría de una sensación anímica más que de un cambio físico, y además sería de carácter auto-referencial: la descripción parece corresponder a un escarabajo, insecto prácticamente doméstico en las casas de la Praga de principios del siglo XX. Además, Kafka en checo significa grajo, mientras que grajo en español -Franz Kafka tenía familia directa en España- significa también escarabajo. Por otra parte, sabemos por sus cartas y diarios personales que el sentirse como un "insecto" era una sensación frecuentemente experimentada por el autor. Incluso algunos críticos han visto en Samsa un anagrama de Kafka, ya que la $S$ en el primer apellido ocupa los mismos lugares que la $\mathrm{K}$ en el segundo.

De acuerdo con la interpretación talmúdica, cabalística, freudiana y en definitiva kafkiana, todo tiene un sentido a escudriñar, existiendo a la vez una multiplicidad de planos de interpretación. En consonancia con esta perspectiva es que se han propuesto diversas lecturas de la transformación. Una de ellas es aquella que vería en sus líneas una descripción de los avatares de un enfermo terminal en el seno de una familia disfuncional.

\section{Ideas directrices}

Las alusiones a la enfermedad circulan a lo largo del texto sugiriendo elípticamente que la transformación relatada podría constituir una alegoría del paso de una persona sana al estado de enfermedad grave, con los cambios individuales, familiares y sociales que ello implica.

."iPor el amor de Dios! - exclamó la madre llorando-, quizás está gravemente enfermo y nosotros 10 atormentamos"...

..."Pero como si se arrepintiera de su conducta, la volvió a abrir al instante y entró de puntillas, como si fuera a ver un enfermo gravisimo"...

El curso de la transformación sufrida por Gregor está signado por el aislamiento y la falta de escucha por parte su familia. De hecho, Samsa en checo significa soledad. No le es brindada ningún tipo de asistencia sanitaria a lo largo de su padecer, en una evidente postura familiar de desidia y abandono.

..." ¿Quién en esta familia sobrecargada de trabajo y de cansancio habría podido ocuparse de Gregor más de lo estrictamente necesario?...

A la comunidad sólo le importa su persona en función de su rol de ente productivo dentro del engranaje social. El peso de esta perspectiva es tal, que incluso el mismo Gregor se ve influenciado por ella, aun en detrimento de si mismo.

."Probablemente vendría el jefe con el médico del Seguro, reprocharía a sus inocentes padres tener un hijo tan holgazán"...

Gregor atraviesa cada uno de los estados anímicos propios del enfermo terminal: negación, esperanza, adaptación al cambio, enojo, depresión y resignación.

\section{Negación}

..."Se acordó de que a veces había sentido algún dolorcillo en la cama, quizá motivado por alguna postura incómoda, y que, al levantarse, había resultado ser pura imaginación. Tenía curiosidad por ver cómo sus imaginaciones de hoy se desvanecían poco a poco. No le cabía ni la duda de que la alteración de voz era el síntoma de un fuerte resfriado "... 


\section{Esperanza}

..."Se sentía otra vez incluido en el círculo de los seres humanos y esperaba, tanto del médico como del cerrajero, obras maravillosas y contundentes... ...Gregor se pasaba las noches y los días casi sin dormir. A veces pensaba que, al abrirse la puerta la próxima vez, él iba a adelantarse para tomar los asuntos de la familia en sus manos, como antes"...

\section{Adaptación a los cambios}

..."Apenas le había sucedido esto cuando, por primera vez en la mañana, se sintió bien. Las patitas estaban en suelo firme y obedecian perfectamente. Incluso se empeñaron en llevarle exactamente adonde él queria..."

\section{Enojo}

..."Otras veces no se sentía en absoluto con humor para ocuparse de la familia y sólo estaba furioso por lo mal que 10 atendían"...

\section{Depresión}

..."Gregor ya casi no comía. Cuando por casualidad pasaba por delante de la comida, tomaba como jugando un bocado, 10 mantenía durante horas en la boca, para escupirlo finalmente"...

\section{Resignación}

..."Pensó con cariño y emoción en los suyos. Su convicción de que tendría que desaparecer era tanto o más firme que la de la hermana. En este estado de tranquilidad y benéfica relajación permaneció hasta que el reloj de la torre de la iglesia dio las tres de la madrugada"...

El enfermo y la enfermedad despiertan en el otro, reacciones diversas e incluso contrapuestas: agresividad, rechazo, temor, compasión, incomprensión, hastío.

\section{Agresividad}

..."dando patadas en el suelo y esgrimiendo bastón y periódico comenzó a espantar a Gregor hacia su habitación. Ninguna súplica valía, ningún ruego fue escuchado. Por humildemente que bajara la cabeza, el padre sólo daba patadas aterradoras"...

\section{Rechazo}

..."Pero ya desde las primeras palabras de Gregor, el Procurador había dado media vuelta, mirándole constantemente por encima del hombro y con un gesto de asco en labios" ...

\section{Temor}

..."Madre, madre", dijo Gregor, alzando los ojos hacia ella.. "Mirándole, la madre dio otro giro, se soltó de la mesa y cayó en los brazos del padre"...

\section{Compasión}

..."Pero jamás habría podido imaginar lo que la hermana hizo con su gran bondad. Para probar sus gustos, le trajo una colección de alimentos y los extendió sobre un periódico"...

\section{Incomprensión}

... "Señor Procurador, no se vaya sin decirme una palabra que me demuestre que me comprende siquiera en alguna pequeña medida". Pero ya desde las primeras palabras de Gregor, el Procurador había dado media vuelta..."

\section{Hastío}

... "Queridos padres -dijo la hermana dando un manotazo en la mesa-, las cosas no pueden seguir así. Si vosotros no lo queréis comprender, yo si lo comprendo. Delante de este monstruo no quiero pronunciar el nombre de mi hermano y por esto sólo digo: Nos lo tenemos que quitar de encima"..

El enfermo pierde potestad, tomando la familia decisiones que, aunque bien intencionadas, avasallan su autonomía.

..."Le vaciaban su habitación; le quitaban lo más querido; el armario donde tenía guardado el serrucho y otras herramientas ya se lo habian llevado"...

El enfermo es víctima de la subestimación por parte de su familia.

... "Si nos entendiera, dijo el padre medio soñando. Pero en medio de su llanto la hermana sólo acertó a agitar enérgicamente la mano en señal de que ni habia que pensar tal cosa. Si nos entendiera -repitió el padre cerrando los ojos como para asimilar mejor la aseveración de la hija de que esto era un imposible"...

La muerte de un individuo no detiene en absoluto los ciclos del mundo.

" Todavía vio el lento amanecer detrás de la ventana. Entonces su cabeza cedió del todo y Gregorio exhaló un débil y último suspiro"...

Este relato embiste intencionalmente además contra dos imaginarios kitsch de la Europa del siglo XIX: por un lado, contra la visión maniqueísta de la seguridad del hogar paterno (hogar dulce hogar) en contraposición con la peligrosidad del mundo exterior, como ve reflejado en diversos pasajes antes mencionados. Por otro lado, la transformación constituye una burla ideal de los "cuentos de hadas" (un anti-Märchen) donde usualmente el héroe transformado en animal es rescatado de su desgracia por efecto del amor. En contraste, en esta obra el "beso salvador" tan anhelado por Gregor jamás llegará.

\section{Conclusión}

La lectura de "La transformación" de Franz Kafka constituye una excelente oportunidad para con vivenciar los avatares que puede sufrir un paciente terminal en el seno de una familia disfuncional.

\section{Bibliografía Recomendada}

Amalfi F. El taller de los escritores. Barcelona. Editorial Océano. 2005

Bloom H. Genios. Bogotá. Grupo Editorial Norma.2005

García-Pelayo y Gross R. Larousse ilustrado. Buenos Aires. Ediciones Larousse Argentina. 1964

Kafka F. La metamorfosis y otros relatos. Buenos Aires. Editorial Planeta. 2000

Kafka F. La metamorfosis. Barcelona. AGEA. 2000

Karothy R. Las metamorfosis de la locura. Buenos Aires. Ediciones de la Campana. 1994

Miralles Contijoch F. El lector de Franz Kafka. Barcelona. Océano. 2000

Murray N. Kafka. Literatura y pasión. Editorial El ateneo. Buenos Aires. 2004

Soderbergh S. Kafka. (film). 1994

Valle P. Lo esencial de Kafka. Buenos Aires. Lumen. 2003 